\title{
Prediction of Maintained Mucosal Healing in Patients with Crohn's Disease under Treatment with Infliximab Using Diffusion-Weighted Magnetic Resonance Imaging
}

\author{
Hirotake Sakuraba ${ }^{a}$ Yoh Ishiguro ${ }^{a, c}$ Keisuke Hasui ${ }^{a}$ Hiroto Hiraga ${ }^{a}$ \\ Shinsaku Fukuda ${ }^{a}$ Koichi Shibutani $^{b}$ Yoshihiro Takai $^{\mathrm{b}}$ \\ Departments of a Gastroenterology and Hematology and ${ }^{b}$ Radiology, Hirosaki University Graduate School of Medicine, \\ and ${ }^{\mathrm{C}}$ Division of Clinical Research, Hirosaki National Hospital, National Hospital Organization, Hirosaki, Japan
}

\section{Key Words}

Magnetic resonance imaging · Infliximab · Crohn's disease ·

Diffusion-weighted imaging

\begin{abstract}
Background: Maintenance of mucosal healing may lead to a better outcome in patients with Crohn's disease (CD). Magnetic resonance diffusion-weighted imaging (MR-DWI) scans 1 year after infliximab (IFX) induction therapy were assessed as predictors of maintained response, or remission, through 3 years of treatment in patients with CD. Summary: MR-DWI and endoscopy data were prospectively collected throughout IFX treatment. Altogether, 86 lesions from 13 patients given IFX as induction (weeks 0,2 and 6) and maintenance $(5 \mathrm{mg} / \mathrm{kg}$ every 8 weeks beginning at week 14$)$ therapy were analyzed with MR-DWI for 0.5-1.5 years from the starting point. Mucosal findings were confirmed by endoscopy at 1 and 3 years (gold standard). Of the 86 lesions, 65 were graded ' 0 ' and 21 were graded ' 1 ' based on their hyperintensity (HI; or lack thereof) on MR-DWI. Two years after the first evaluation, 7 of 15 false-negative lesions had turned positive based on colonoscopy findings, and 60 of 62 true-negative lesions had not. Thus, $0.03 \%$ of those predicted to remain in remission had relapsed (negative predictive value 0.9677 ,
\end{abstract}

$\mathrm{p}<0.0001$ ). MR-DWI-HI at 1 year coincided with the presence of endoscopic inflammation, with sensitivity of $66.67 \%$, specificity of $80.52 \%$, and an area under the curve (AUC) value of $0.7359(0.5479-0.9240, p=0.0211)$. The AUC value of MR-DWI-HI at 3 years was $0.8402(0.7460-0.9343, p=0.001)$ with sensitivity of $94.12 \%$ and specificity of $73.91 \%$. Key Message: A definition of the response on the basis of MR-DWI-HI might be helpful for optimizing treatment for patients with CD under treatment with IFX.

(c) 2014 S. Karger AG, Basel

\section{Introduction}

Intestinal complications of Crohn's disease (CD) are progressive in the presence of chronic persistent inflammation. Consequently, the operative rate is estimated to be $80 \%$ at 20 years after onset of the disease [1-3]. After surgery, $40 \%$ of patients are symptomatic within 4 years [4], and many patients $(\approx 30 \%)$ experience disease recurrence and require a second operation within 10 years [5]. In an attempt to avoid multiple operations, several trials

H.S. and Y.I. contributed equally to this work.

\section{KARGER}

E-Mail karger@karger.com www.karger.com/dig (c) 2014 S. Karger AG, Base

$0012-2823 / 14 / 0891-0049 \$ 39.50 / 0$
Yoh Ishiguro, Department of Gastroenterology and Hematology

Hirosaki University Graduate School of Medicine

Division of Clinical Research, Hirosaki National Hospital, National Hospital Organization 5-Zaifu-cho, Hirosaki 036-8562 (Japan)

E-Mail yishi-hki@umin.ac.jp 
Table 1. Patient characteristics

\begin{tabular}{|c|c|c|c|c|c|c|c|c|c|c|c|c|c|}
\hline \multirow[t]{2}{*}{$\begin{array}{l}\text { Case } \\
\text { No. }\end{array}$} & \multirow[t]{2}{*}{$\begin{array}{l}\text { Age, } \\
\text { years }\end{array}$} & \multirow[t]{2}{*}{ Sex } & \multirow{2}{*}{$\begin{array}{l}\text { Disease } \\
\text { duration, } \\
\text { years }\end{array}$} & \multirow[t]{2}{*}{$\begin{array}{l}\text { Disease } \\
\text { location }\end{array}$} & \multirow[t]{2}{*}{$\begin{array}{l}\text { Disease } \\
\text { behavior }\end{array}$} & \multirow[t]{2}{*}{$\begin{array}{l}\text { Medication } \\
\text { before inclusion }\end{array}$} & \multirow[t]{2}{*}{$\begin{array}{l}\text { Surgery before } \\
\text { inclusion }\end{array}$} & \multicolumn{3}{|c|}{$\begin{array}{l}\text { CDAI from the start } \\
\text { point }\end{array}$} & \multicolumn{3}{|c|}{$\begin{array}{l}\text { CRP from the start } \\
\text { point, } \mathrm{mg} / \mathrm{dl}\end{array}$} \\
\hline & & & & & & & & before & 1 year & 3 years & befor & 1 year & 3 years \\
\hline 1 & 44 & $\mathrm{~F}$ & 20.4 & Ileocolonic & Inflammatory & 5ASA, GC, MNZ & Seton drainage & 236 & 124 & 86 & 0.1 & 0.1 & 0.01 \\
\hline 2 & 34 & M & 16.8 & Ileocolonic & Stenotic & 5ASA, AZA, GC, ED & $\begin{array}{l}\text { Ileocecal resection, seton } \\
\text { drainage }\end{array}$ & 314 & 335 & 139 & 0.1 & 1.0 & 1.1 \\
\hline 3 & 38 & $\mathrm{M}$ & 15.3 & Ileocolonic & Inflammatory & 5ASA, 6MP, GC & - & 119 & 51 & 51 & 3.4 & 0.29 & 0.44 \\
\hline 6 & 26 & $\mathrm{~F}$ & 4.2 & Ileocolonic & Inflammatory & $5 \mathrm{ASA}$ & - & 176 & 62 & 164 & 0.9 & 0.1 & 0.32 \\
\hline 7 & 26 & M & 7.8 & Ileocolonic & Inflammatory & 5ASA, GC & - & 149 & 70 & 73 & 3.5 & 0.03 & 0.02 \\
\hline 8 & 25 & M & 7.7 & Ileocolonic & Inflammatory & 5ASA, GC, MNZ & - & 287 & 25 & 11 & 2.1 & 0.05 & 0.95 \\
\hline 9 & 23 & M & 6.9 & Ileocolonic & Stenotic & 5ASA, 6MP, ED & - & 98 & 83 & 56 & 0.4 & 0.06 & 0.411 \\
\hline 10 & 34 & M & 7.6 & Ileocolonic & Penetrating & 5ASA, ED & Ileocecal resection & 158 & 100 & 134 & 0.4 & 0.11 & 0.79 \\
\hline 11 & 12 & $\mathrm{~F}$ & 4.8 & Ileocolonic & Inflammatory & 5ASA, ED & - & 138 & 90 & 67 & 0.1 & 0.1 & 0.1 \\
\hline
\end{tabular}

$\mathrm{CDAI}=\mathrm{CD}$ activity index; $5 \mathrm{ASA}=5$-aminosalicylate $\mathrm{GC}=$ glucocorticoids; $\mathrm{MNZ}=$ metronidazole; $6 \mathrm{MP}=6$-mercaptopurine; $\mathrm{AZA}=$ azathioprine; $\mathrm{ED}=$ elemental diet.

of nonsurgical treatment for stenosis have been performed. Immunosuppressant [6] and biological [7, 8] therapies might reduce the need for surgery but must be given early in disease progression, before the development of irreversible anatomical lesions [9]. Infliximab (IFX) treatment seems to be effective for preventing the development of new anastomotic lesions defined by endoscopic findings at 1 year [10]. These recent experiences and clinical trials have substantiated that the decreased disease activity achieved by the induction of biological agents is likely to achieve a better outcome.

Despite recent developments in diagnostic imaging, the issue of defining minimal activity in $\mathrm{CD}$ patients remains confusing. Hence, there is some concern that the disease is underreported, especially during its early course, which might result in missing critical windows within which to identify ways to better treat the individual patient. Because CD lesions are progressive and are characterized as transmural inflammation, anticipation of the lesion before it becomes irreversible and detecting it in areas not limited to changes in the mucosal surface might shed light on the therapeutic strategy.

In this respect, magnetic resonance diffusion-weighted imaging (MR-DWI) well characterizes the presence of active CD lesions. Its sensitivity is $58.33 \%$, and its specificity is $84.48 \%$ [ 11 ].

We evaluated whether prospective use of MR-DWI and endoscopy would predict mucosal healing. For this purpose, we addressed each segment of the colon and (neo) terminal ileum, assessing them with both MR-DWI and endoscopy. We showed that radiologically the lack of MR-DWI hyperintensity (HI) after treatment would predict the maintenance of (continued) mucosal healing for the next 2 years.

\section{Patients and Methods}

This study was performed during the period 2009-2012 at Hirosaki University Hospital. Institutional review board approval was obtained, and informed consent was waived.

$\mathrm{CD}$ was diagnosed according to the criteria provided by the Investigation and Research Committee for Intractable Inflammatory Bowel Disease organized by the Japanese Ministry of Public Welfare, as described previously [12, 13]. The patients' medical histories, including abdominal and extra-abdominal complaints, associated disease, CD behavior and the CD activity index, location of CD lesions, duration of the disease, past surgery, endoscopic dilatation, and current and previous medical treatment, were obtained.

\section{Inclusion Criteria}

A total of $13 \mathrm{CD}$ patients were included in the study. Their baseline demographic and clinical characteristics are shown in table 1 .

\section{Exclusion Criteria}

Exclusion criteria included pregnancy and general contraindications to IFX or radiology-based examinations. Patients with abscesses, ileoileal fistulas or ileocolonic fistulas were also excluded. 
Table 2. Sensitivity, specificity, positive and negative predictive values of MR-DWI-HI for endoscopic activity after 1 year of IFX treatment

\begin{tabular}{llll}
\hline Data analyzed & $\begin{array}{l}\text { Endoscopic } \\
\text { activity positive }\end{array}$ & $\begin{array}{l}\text { Endoscopic } \\
\text { activity negative }\end{array}$ & Total \\
\hline MR-DWI-HI positive & 6 & 15 & 21 \\
MR-DWI-HI negative & 3 & 62 & 65 \\
Total & 9 & 77 & 86 \\
\hline Sensitivity (95\% CI) & $0.6667(0.2993-0.9251)$ & \\
Specificity (95\% CI) & $0.8052(0.6991-0.8867)$ & \\
PPV (95\% CI) & $0.2857(0.1128-0.5218)$ & \\
NPV (95\% CI) & $0.9538(0.8710-0.9904)$ & \\
Likelihood ratio & 3.422 & & \\
\end{tabular}

Fisher's exact test was used to evaluate the contingency analysis for MR-DWI-HI and the endoscopic findings. PPV = Positive predictive value; NPV = negative predictive value.

\section{Treatment}

Patients were scheduled to receive infusions of IFX $(5 \mathrm{mg} / \mathrm{kg})$ at 0,2 and 6 weeks (induction phase), followed by $5 \mathrm{mg} / \mathrm{kg}$ every 8 weeks thereafter (maintenance phase). Continued use of drugs already being taken, such as salicylates and/or immunomodulators, was permitted during the intervals between evaluations.

\section{Evaluation}

The MRI examinations were performed as described previously [11]. Briefly, MRI scans were obtained using a 1.5-T GE Signa HDXt scanner (GE Healthcare, Waukesha, Wis., USA) with phased-array body coils. The protocol comprised a 2-dimensional single-shot fast spin echo short echo time sequence in the axial and coronal planes, a 2-dimensional steady-state free precession with fat saturation in the coronal plane, and a diffusion-weighted sequence in the axial plane. The diffusion-weighted sequence employed a diffusion factor $b$ fixed at $800 \mathrm{~s} / \mathrm{mm}^{2}$ and provided 2 sets of images, 1 for the expected $b$ value and another for $b=0$. The acquisition was performed in the axial plane using a field of view ranging from 35 to $40 \mathrm{~cm}$ and a $7-\mathrm{mm}$ slice thickness with a 1.4$\mathrm{mm}$ gap in respiratory triggering. Two stations were needed to cover the abdomen and the pelvis. The duration of the entire examination was less than $20 \mathrm{~min}$.

Seven segments were identified for MR-DWI colonography analysis: rectum, sigmoid, left colon, transverse colon, ascending colon, cecum and ileum. Partially resected segments were not included in the study. During the maintenance phase, the presence and absence of radiological signs of MR-DWI-HI in a given segment were rated ' 1 ' and ' 0 ', respectively. The mucosal lesions in a given segment were confirmed on endoscopy (CF-SV-L; Olympus Medical Systems, Tokyo, Japan) as the diagnostic gold standard.

A total of 86 lesions from 13 patients were assessed by MRDWI and endoscopy before each scheduled IFX infusion. These examinations were performed 1 and 3 years after the starting point of the IFX therapy. The median interval between MR-DWI and endoscopy was 3 months (95\% confidence interval, CI, 2-6) at 1
Table 3. Negative predictive value of MR-DWI-HI at 1 year for endoscopic remission over the next 2 years

\begin{tabular}{llll}
\hline Data analyzed & $\begin{array}{l}\text { Endoscopic } \\
\text { relapse (3 years) }\end{array}$ & $\begin{array}{l}\text { Endoscopic } \\
\text { remission (3 years) }\end{array}$ & Total \\
\hline MR-DWI-HI & & & \\
$\quad$ positive (1 year) & 7 & 60 & 15 \\
$\quad$ negative (1 year) & 2 & 68 & 62 \\
Total & 9 & & \\
\hline Sensitivity (95\% CI) & $0.7778(0.3999-0.9719)$ & \\
Specificity (95\% CI) & $0.8824(0.7813-0.9478)$ & \\
PPV (95\% CI) & $0.4667(0.2127-0.7341)$ & \\
NPV (95\% CI) & $0.9677(0.8883-0.9961)$ & \\
Likelihood ratio & 6.611 & & \\
\end{tabular}

Fisher's exact test was used to evaluate the contingency analysis for MR-DWI-HI and the endoscopic findings. PPV = Positive predictive value; NPV = negative predictive value.

year, and 3 months (95\% CI 2-4) at 3 years. The C-reactive protein (CRP) level was evaluated just before each IFX infusion. The data were collected prospectively.

Statistical Analysis

A p value $<0.05$ was considered statistically significant in all analyses. Probability values and confidence intervals were calculated at the 95\% level. Fisher's exact test was used to evaluate the contingency analysis for MR-DWI-HI and the endoscopic findings.

Receiver operating characteristic (ROC) analysis was performed to compare the diagnostic performance of the parameters. The area under the ROC curve (AUC) was used to choose a threshold value for each test parameter by maximizing the combination of sensitivity and specificity.

\section{Results}

\section{Lesion Detection, Negative Predictive Value, ROC Analysis}

Of the 86 lesions evaluated in this study, 65 were graded ' 0 ' and 21 were graded ' 1 ' based on MR-DWI-HI. Among those lesions, 6 of 21 positive lesions were also positive on colonoscopy (true positive), but 15 lesions were not (false positive; table 2). Of the $65 \mathrm{MR}-\mathrm{DWI}-\mathrm{HI}-$ negative lesions, 3 were positive on colonoscopy (false negative; table 2). Thus, MR-DWI-HI predicted the presence of synergistic mucosal changes on colonoscopy with a sensitivity of $80.52 \%$ and specificity of $66.67 \%$ ( $\mathrm{p}=$ 0.0018 ; table 2). 
Fig. 1. Effect of IFX on maintaining mucosal healing as evaluated with MR-DWI and endoscopy. MR-DWI shows hyperintensity in the bowel wall before IFX therapy (a) and its virtual disappearance after $1(\mathbf{b})$ and 3 (c) years of treatment. Coexistence of longitudinal ulcers on the transverse colon (d) indicates active inflammation before IFX therapy. Coincident with MR-DWI, endoscopic findings at $1(\mathbf{e})$ and $3(\mathbf{f})$ years of treatment show no active lesions, suggesting the usefulness of MR-DWI hyperintensity as a marker for prognosticating outcome.

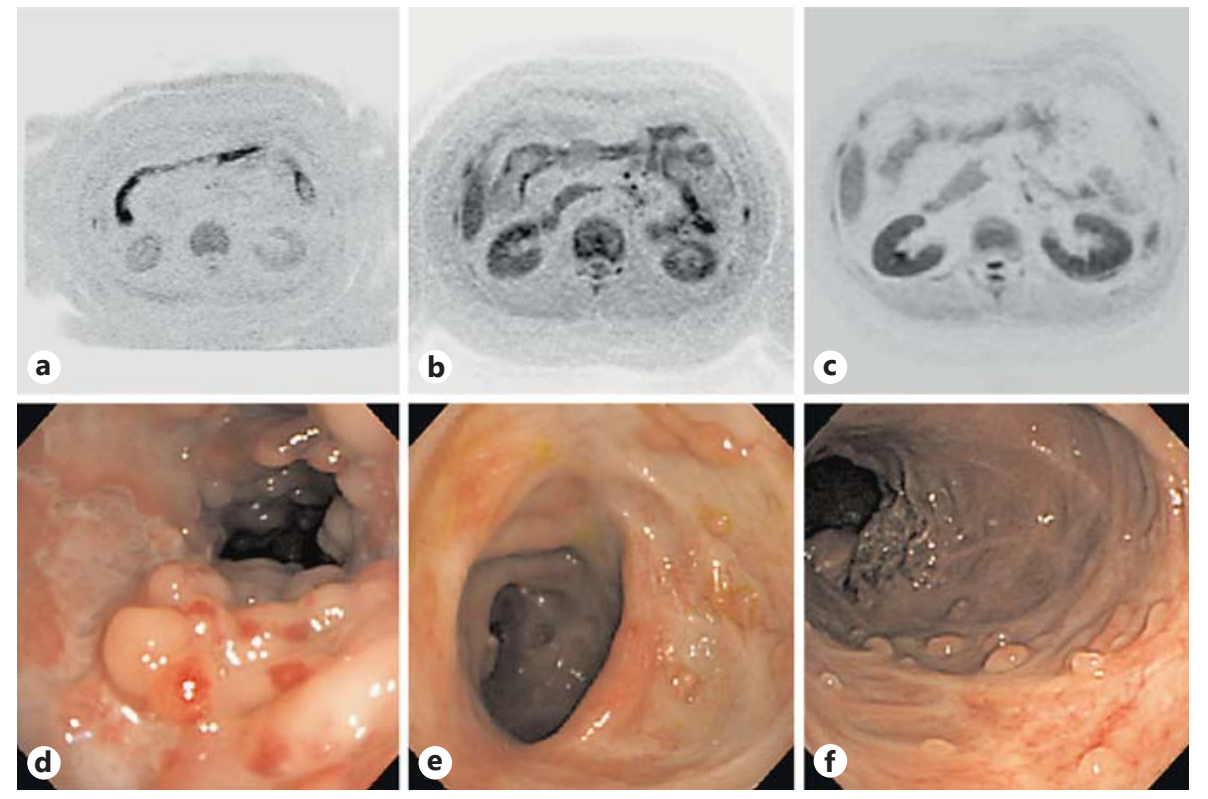

Two years after the first evaluation, 7 of the 15 falsepositive lesions had turned true positive on colonoscopy, and 60 of the 62 true-negative lesions had not (i.e. case 7; fig. 1; table 3). Thus, $0.03 \%$ of those predicted to remain in remission had relapsed (negative predictive value $0.9677, \mathrm{p}<0.0001$ ), and $46.7 \%$ of those predicted to relapse did so (table 3).

MR-DWI-HI at 1 year was able to predict the presence of endoscopic inflammation with a sensitivity of $66.67 \%$, specificity of $80.52 \%$ and AUC value of 0.7359 (95\% CI $0.5479-0.9240, \mathrm{p}=0.0211$; fig. 2). Also, MR-DWI-HI at 3 years suggested endoscopic inflammation with sensitivity of $94.12 \%$, specificity of $73.91 \%$, and AUC value of 0.8402 (95\% CI 0.7460-0.9343, $\mathrm{p}=0.001$; fig. 2 ).

\section{Discussion}

Using endoscopy as the reference standard, we evaluated the accuracy of MR-DWI for assessing disease extent and severity in $86 \mathrm{CD}$ lesions under IFX treatment. The study demonstrated that MR-DWI-HI negatively predicted the development of endoscopic remission over the following 2 years. MR-DWI is sensitive to molecular diffusion based on the Brownian motion of the spins in biological tissue. It derives its image contrast from differences in the motion of water molecules between tissues [14]. The feasibility of using MR-DWI in CD patients has been assessed, and it is now being explored for evaluating

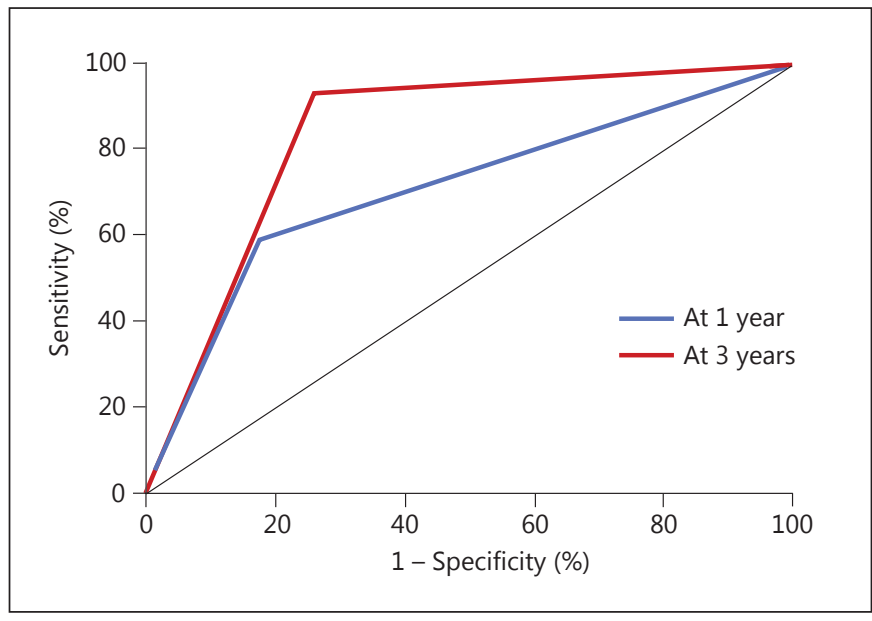

Fig. 2. ROC analysis for the coexistence of inflammation as defined by MRI and endoscopy. The ROC curve analysis of MR-DWI-HI prediction for the presence of endoscopic inflammation was evaluated 1 and 3 years from the starting point of IFX treatment.

the disease. In addition to being able to estimate the accuracy of MR-DWI for detecting mucosal lesions, we hypothesized that MR-DWI-HI negativity might be associated with continuing response to treatment.

Our major concern was the underreporting of disease activity, especially during the early course of CD. It might lead to missing critical windows wherein we could identify site-specific markers, rather than general biomarkers, 
that would contribute to tailoring treatment strategies for the individual patient. In this respect, our study revealed that $0.03 \%$ of those predicted to remain in remission do, in fact, relapse. Also, $46.7 \%$ of those predicted to relapse become truly positive for $\mathrm{CD}$ over the following 2 years (table 3 ). As a result, MR-DWI at 3 years reflected endoscopic findings with more accuracy using the AUC value (fig. 2). Thus, our study demonstrated the usefulness of MR-DWI for identifying treatment markers.

Aside from imaging, many laboratory data are available regarding predictors of response for short- and longterm clinical benefit during therapy with biological agents [15-17]. Survival analysis demonstrated that patients in whom CRP levels normalized early (after 4 weeks of a 10week period) had better long-term outcomes. The CRP level at the time of endoscopy significantly correlated with the degree of mucosal healing $[16,17]$. The positive predictive value of $51.8 \%$ for continuing remission at 54 weeks means that a clinician could predict a 1-year response in a patient. It is notable that the positive predictive values for the 3-month CRP level for predicting a response at 1 year are similar to those found previously [18]. Therefore, a negative CRP test was identified as a predictor for sustained clinical benefit for 1 year, but $25 \%$ of those predicted to remain in remission did relapse, and only $22 \%$ of those predicted to relapse did so [19]. The present study defined that, at 1 year, negative MR-DWIHI might correlate with continuing remission during 3 years of IFX treatment (i.e. case 7; fig. 1). This potential for anticipating endoscopic recurrence was equivalent to that of CRP, even in our study. The additional beneficial potential of MR-DWI was the identification of inflamma- tory lesions noninvasively. Taken together, MR-DWI-HI would be useful in CRP-positive cases to define the site of inflammation and recurrence before the patient undergoes colonoscopy.

Our study included only a small number of patients from a single center, but the data were collected prospectively with 3-year follow-up periods. Further long-term study is needed to clarify the potential of MRI for identifying treatment markers on a large scale. Concomitant with recent advances in new biologic therapy [2], such a study might define true indications of modification under treatment with biological agents for CD.

\section{Conclusion}

A definition of the response to treatment based on MR-DWI findings might be helpful for optimizing the indications for endoscopy and further treatment of CD patients.

\section{Acknowledgements}

This study was supported by Health and Labour Sciences Research Grants for Research on Intractable Diseases from the Ministry of Health, Labour, and Welfare of Japan.

\section{Disclosure Statement}

The study was not supported by any pharmaceutical company. The authors have no conflicts of interests to declare.

\section{References}

1 Solberg IC, Vatn MH, Hoie O, Stray N, Sauar J, Jahnsen J, Moum B, Lygren I: Clinical course in Crohn's disease: results of a Norwegian population-based ten-year follow-up study. Clin Gastroenterol Hepatol 2007;5: 1430-1438.

2 Hamilton MJ, Snapper SB, Blumberg RS: Update on biologic pathways in inflammatory bowel disease and their therapeutic relevance. J Gastroenterol 2012;47:1-8.
3 Sands BE, Arsenault JE, Rosen MJ, Alsahli M, Bailen L, Banks P, Bensen S, Bousvaros A, Cave D, Cooley JS, Cooper HL, Edwards ST, Farrell RJ, Griffin MJ, Hay DW, John A, Lidofsky S, Olans LB, Peppercorn MA, Rothstein RI, Roy MA, Saletta MJ, Shah SA, Warner AS, Wolf JL, Vecchio J, Winter HS, Zawacki JK: Risk of early surgery for Crohn's disease: implications for early treatment strategies. Am J Gastroenterol 2003;98:27122718.

4 Rutgeerts P, Geboes K, Vantrappen G, Beyls J, Kerremans R, Hiele M: Predictability of the postoperative course of Crohn's disease. Gastroenterology 1990;99:956-963.
5 Munkholm P, Langholz E, Davidsen M, Binder V: Disease activity courses in a regional cohort of Crohn's disease patients. Scand J Gastroenterol 1995;30:699-706.

6 6 Picco MF, Zubiaurre I, Adluni M, Cangemi JR, Shelton D: Immunomodulators are associated with a lower risk of first surgery among patients with non-penetrating non-stricturing Crohn's disease. Am J Gastroenterol 2009; 104:2754-2759.
DW-MRI Prediction of Mucosal Healing in CD Patients Treated with IFX 
7 Lichtenstein GR, Olson A, Travers S, Diamond RH, Chen DM, Pritchard ML, Feagan BG, Cohen RD, Salzberg BA, Hanauer SB, Sandborn WJ: Factors associated with the development of intestinal strictures or obstructions in patients with Crohn's disease. Am J Gastroenterol 2006;101:1030-1038.

-8 Feagan BG, Panaccione R, Sandborn WJ, D'Haens GR, Schreiber S, Rutgeerts PJ, Loftus EV Jr, Lomax KG, Yu AP, Wu EQ, Chao J, Mulani P: Effects of adalimumab therapy on incidence of hospitalization and surgery in Crohn's disease: results from the CHARM study. Gastroenterology 2008; 135:14931499.

$>9$ Lemann M, Mary JY, Colombel JF, Duclos B, Soule JC, Lerebours E, Modigliani R, Bouhnik Y: A randomized, double-blind, controlled withdrawal trial in Crohn's disease patients in long-term remission on azathioprine. Gastroenterology 2005;128:1812-1818.

10 Regueiro M, Schraut W, Baidoo L, Kip KE, Sepulveda AR, Pesci M, Harrison J, Plevy SE: Infliximab prevents Crohn's disease recurrence after ileal resection. Gastroenterology 2009; 136:441-450.
11 Oussalah A, Laurent V, Bruot O, Bressenot A, Bigard MA, Regent D, Peyrin-Biroulet L: Diffusion-weighted magnetic resonance without bowel preparation for detecting colonic inflammation in inflammatory bowel disease. Gut 2010;59:1056-1065.

$\$ 12$ Yao T, Matsui T, Hiwatashi N: Crohn's disease in Japan: diagnostic criteria and epidemiology. Dis Colon Rectum 2000;43:S85-S93.

13 Ueno F, Matsui T, Matsumoto T, Matsuoka K, Watanabe M, Hibi T: Evidence-based clinical practice guidelines for Crohn's disease, integrated with formal consensus of experts in Japan. J Gastroenterol 2013;48:31-72.

14 Laurent V, Trausch G, Bruot O, Olivier P, Felblinger J, Regent D: Comparative study of two whole-body imaging techniques in the case of melanoma metastases: advantages of multicontrast MRI examination including a diffusion-weighted sequence in comparison with PET-CT. Eur J Radiol 2010;75:376-383.

15 Imaeda H, Bamba S, Takahashi K, Fujimoto T, Ban H, Tsujikawa T, Sasaki M, Fujiyama Y, Andoh A: Relationship between serum infliximab trough levels and endoscopic activities in patients with Crohn's disease under scheduled maintenance treatment. J Gastroenterol 2013, E-pub ahead of print.
6 Koelewijn CL, Schwartz MP, Samsom M, Oldenburg B: C-reactive protein levels during a relapse of Crohn's disease are associated with the clinical course of the disease. World J Gastroenterol 2008;14:85-89.

17 Louis E, Vermeire S, Rutgeerts P, De Vos M, Van Gossum A, Pescatore P, Fiasse R, Pelckmans P, Reynaert H, D'Haens G, Malaise M, Belaiche J: A positive response to infliximab in Crohn disease: association with a higher systemic inflammation before treatment but not with -308 tnf gene polymorphism. Scand J Gastroenterol 2002;37:818-824.

18 Reinisch W, Wang Y, Oddens BJ, Link R: Creactive protein, an indicator for maintained response or remission to infliximab in patients with Crohn's disease: a post-hoc analysis from ACCENT I. Aliment Pharmacol Ther 2012;35:568-576.

19 Card T: Commentary: is CRP ready for use to indicate response or remission with infliximab in Crohn's? Aliment Pharmacol Ther 2012;35:960-962. 